\title{
A comparative study on the rheological properties of coal water slurries using sodium tripoly-phosphate and carboxy-methyl-cellulose as dispersants
}

The effects of two anionic dispersants (polymeric-carboxy methyl cellulose: CMC and inorganic-sodium tripolyphosphate: STPP) on the rheological properties of coal water slurries (CWS) of varying solid loading were reported and compared. The rheological data was obtained in the shear rate range of 60-160 $\mathrm{s}^{-1}$ and the data was fitted using power law model. For lower solid concentrations (10\% and 20\%), shear thickening behaviour was observed while shear thinning nature was seen for the higher solid loadings (30\%,40\% and 50\%) for CWS with both the dispersants. For all slurries, an increase in flow behaviour index values was seen with the increase of dispersant loading. For CWS of $10 \%$ and $20 \%$ solid loadings, lower values of flow behaviour index was observed with CMC as dispersant. On the other hand, lower values for flow behaviour index was seen with STPP as dispersant for CWS of 30\%, 40\% and $50 \%$ solids loading. Although CMC was found very effective in reducing the apparent viscosity at lower dosages unlike STPP, the apparent viscosity values are quite sensitive to the loading of CMC as dispersant in comparison to STPP. This observed trend may be due to aggressively induced negative charges upon the adsorption of CMC on coal particles at the tested dispersant dosages.

Keywords: Coal water slurry, high ash Indian coals, sodium tripoly-phosphate (STPP), carboxy-methyl-cellulose $(C M C)$, rheology, flow behaviour index.

\subsection{Introduction}

$\mathrm{T}$ The transportation of coal as coal water slurry (CWS) is a proven technology and coal is being majorly used in the commercial energy generation sector worldwide

Blind peer reviews carried out

Dr. M. Ananda Rao, CSIR-National Metallurgical Laboratory, Madras Centre, CSIR Complex, Taramani, Chennai 600113, Dr. M.V. Pavan Kumar, Department of Chemical Engineering. National Institute of Technology Calicut, Kozhikode, Kerala State and Mr. Lenka Srinu, CSIR-National Metallurgical Laboratory, Madras Centre, CSIR Complex, Taramani, Chennai 600113, India. E-mail: E-mail: anandm04@gmail.com / malladi@nitc.ac.in / srinuminpro@gmail.com
$[1,2]$. In India, although the available coal from the reserves is of non-coking or low rank coal type, they are suitable for gasification and combustion [3]. For this purpose, preparation of coal water slurry (CWS) of suitable flow characteristics is quite essential for easy transportation during the unit operations stage. Hence, the study of rheological properties of CWS becomes obvious for the design and optimisation of the coal utilization in the energy generation. For the slurry, higher coal concentration, minimum viscosity, lower yield stress and minimum settling are desirable for the better efficiencies of handling and operations [4]. For the desirable properties of CWS it is proven that the addition of suitable chemical dispersants or additives is an easy way out for the reduction of slurry viscosity successful maintenance of fluidity and impartation of stability $[5,6]$.

The addition of chemical additives can induce electrostatic or steric repulsions among the coal particles with negative charges on the coal particle's surface. Several types of dispersants (anionic, non-ionic, polymeric and natural etc) for coal water slurries were successfully tested and reported in the literaure [7-9]. Nevertheless very few works reported the comparison of the effect of two distinct dispersants for the coal water slurries for a coal sample to detail the workings of dispersants and thereby correlating their impact on the observed rheological behaviour. In this contribution, two anionic dispersants (inorganic and polymeric) are employed in the preparation of CWS and the effect of these dispersants on the rheological properties were compared.

For CWS, the dispersants also known as additives (ionic and non-ionic) are added in small proportions to decrease the interfacial tension between coal particles and water [10-13]. The anionic dispersants create net negative charge on the coal surface by the adsorption of the hydrophobic tail portion of the dispersant/additive over the coal surface with negatively charged head protruding out from the surface after dissociation or formation of stable surface complex with high valence cations of the coal matrix on the surface (e.g. $\mathrm{Al}^{3+}, \mathrm{Fe}^{3+}$ ) [1]. 
On the other hand, anionic polymeric dispersants effectively stabilize the coal water slurries by the combination of steric and electrostatic repulsive forces with high molecular adsorbent layer formed on the surface of coal particle [14-17].

The current study presents a quantitative comparison of the apparent viscosity of coal water suspensions prepared separately using the two anionic dispersants namely carboxy methyl cellulose (CMC) and sodium tripoly-phosphate (STPP) for an Indian coal variety. The rheological properties were compared for different solid loadings at a constant $\mathrm{pH}$ value of 9 .

\subsection{Experimental}

After collecting the coal sample from Jamadoba mine of Jharkhand state, the coal sample was air dried and ground to the size of $\mathrm{D}_{80}=56$ microns and directly used in the preparation of CWS. Proximate and ultimate analysis of the coal was performed as per the ASTM standard procedure and the results are shown in Table 1.

Table 1: Proximate analysis of COAL

\begin{tabular}{ll}
\hline Test & Result \\
\hline Moisture (ADB) & $0.8 \%$ \\
Volatile matter (ADB) & $19.9 \%$ \\
Ash (ADB) & $30.2 \%$ \\
Fixed Carbon (ADB) & $49.1 \%$ \\
GCV (ADB) & $5537 \mathrm{Kcal} / \mathrm{kg}$ \\
ADB-Air dry basis & \\
\hline
\end{tabular}

The representative samples of CWS were prepared using the standard sampling procedure. The two chemical additives namely sodium tripoly phosphate (STPP) and carboxy methyl cellulose (CMC) of lab grade were employed as dispersants in this work. Using turbidity and zeta potential measurements on the mixture of coal powder, distilled water and the dispersant, the suitability and effectiveness of these two dispersants were estimated using Digital Nephelo Turbidity Meter 132 and Beckman Coulter Delsa ${ }^{\mathrm{TM}}$ Nano C Particle Analyzer respectively.

The coal sample morphology and the phase distribution were examined using Scanning Electron Microscopy (SEM)EDS mapping. To the tap water, material and additives (dispersant, $\mathrm{pH}$ modifiers) were added in the predetermined proportions to make standardised slurries of $100 \mathrm{ml}$ in volume. The slurries were homogenised by stirring for $15 \mathrm{~min}$. Using cup and bob Rheolmeter, the rheological properties of the slurries were obtained in the shear rate range of $60-160 \mathrm{~s}^{-1}$.

Coal water slurries of five different solids concentration $(10 \%, 20 \%, 30 \%, 40 \%$ and $50 \%)$ were prepared for each dispersant. In the case of STPP as dispersant, four distinct concentrations $(2,4,6$ and $8 \mathrm{~kg} /$ tonne) were chosen in the preparation of a CWS of given solids concentration. Similarly, the four concentrations for $\operatorname{CMC}(0.5,1.0,1.5$ and $2.0 \mathrm{~kg} /$ tonne) were employed. As mild alkaline conditions ( $\mathrm{pH}$ in the range of 8-9) with overall negative charge on the coal surface is preferred for the coal in the coal processing unit operations [1], the $\mathrm{pH}$ of CWS was fixed at 9 in all experiments. The rheological data was fitted for Osawald de Waele model and the parameters of the model were calculated.

\subsection{Results and discussion}

The material characterization of coal and an understanding of the physical and chemical properties including composition are quite essential to correlate the action of additives or dispersants and subsequent rheological properties of CWS. The proximate and ultimate analysis of the coal was given in Table 1. The particle size distribution (PSD) of the grounded coal was given in Table 2.

Table 2: Size analysis of CoAl SAmple

\begin{tabular}{lc}
\hline Mesh size & $\begin{array}{l}\text { Cumulative weight \% } \\
\text { (Pass through) }\end{array}$ \\
\hline+150 & 100 \\
$-150+105$ & 98.49 \\
$-105+74$ & 90.01 \\
$-74+53$ & 78.29 \\
$-53+38$ & 70.37 \\
$-38+25$ & 58.82 \\
$-25+16$ & 47.78 \\
$-16+11$ & 39.58 \\
$-11+5$ & 24.03 \\
$-5+4$ & 20.47 \\
-4 & 0 \\
\hline
\end{tabular}

The morphology of the coal and its chemical distribution of phases were analysed using Scanning Electron Microscopy (SEM) with energy dispersive X-ray spectroscopy (EDS) elemental mapping. Fig.1 shows the SEM micrograph of coal sample with the elemental mapping. The analysis confirms the presence of both carbonaceous mineral with carbon and non-carbonaceous mineral matter with oxygen, silicon, iron, aluminum, calcium and sulphur as dominating elements. The presence of these elements suggests the occurrence of quartz, kaolinite, pyrite and montimorillonite etc. as non-carbonaceous mineral matter in the coal sample.

\subsection{Zeta POTENTIAL AND TuRbidity MEASUREMENTS}

The knowledge on zeta potential and turbidity of the coal in the presence of chemical additive or dispersant can greatly help in the favourable manipulation of rheological properties of the CWS. Zeta potential and turbidity measurements were carried out on the coal samples with the addition of each dispersant (CMC and STTP) and the results are presented in Figs. 2 and 3 respectively. A continuous increase in the turbidity and a gradual decrease in zeta potential with the 


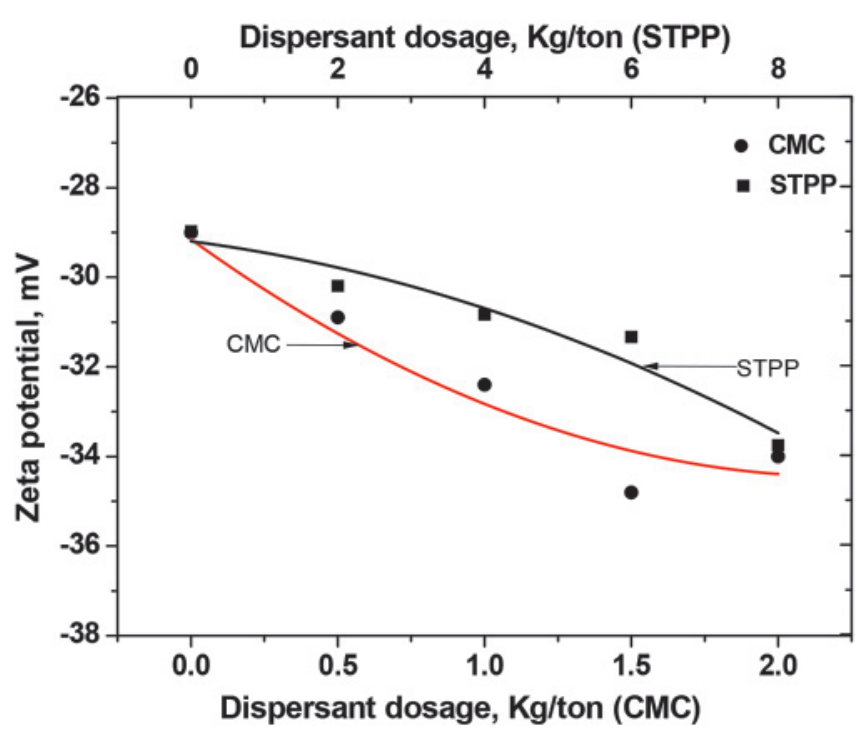

Fig.1: Zeta potential of the coal as a function of CMC and STPP as a dispersant

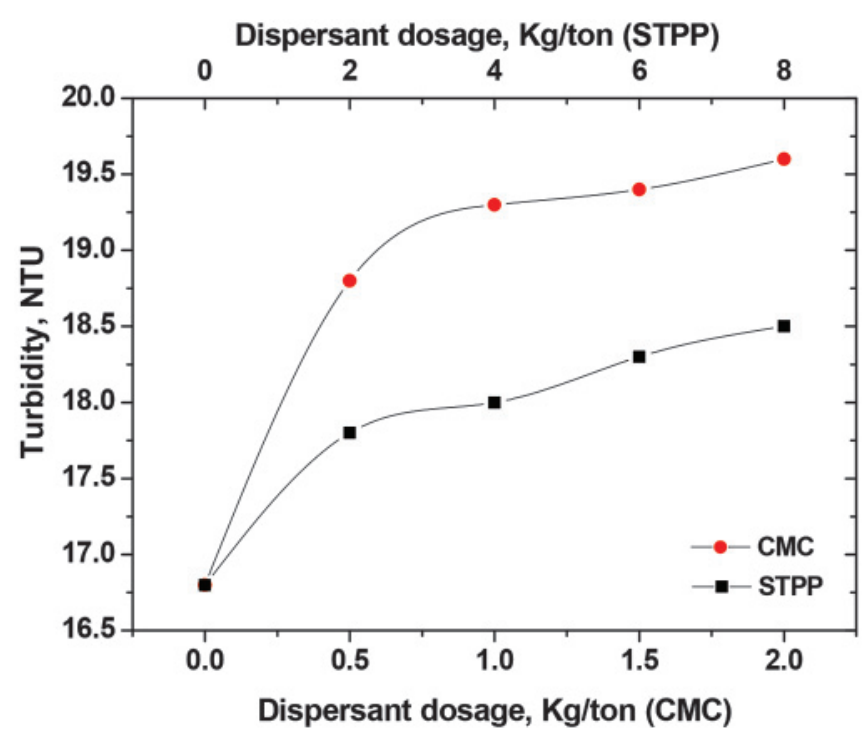

Fig.2: Turbidity of the coal as a function of CMC and STPP as a dispersant

gradual addition of dispersant was observed for both the dispersants. A maximum turbidity value of 18.5 NTU was obtained for $8 \mathrm{~kg} /$ tonne STPP addition while a slightly higher turbidity value (18.9 NTU) was obtained with only $0.5 \mathrm{~kg}$ / tonne addition of $\mathrm{CMC}$ in comparison as shown in Fig.3. Overall, the higher turbidity and lower zeta potential values for CMC in comparison with STPP in the range of loadings tested indicate the higher effectiveness of CMC as dispersant. A lower value of zeta potential with a higher value of turbidity can be seen in the form of lowered viscosity and even dispersion which are quite beneficial for the slurry transportation [18].

\subsection{DiSPERSANT EFFECT ON FLOW PROPERTIES}

The variation of apparent viscosity with respect to shear rate and a comparison of the rheological behaviours was depicted for the two dispersants (CMC and STPP) in Fig.4 (a)-(j). In all cases, non-Newtonian behaviour was clearly evident. Linear equation fit was applied to calculate the slope and to estimate the nature of flow behaviour. For a given dispersant dosage, the apparent viscosity values of CWS increased with respect to the increase in shear rate for the CWS of lower concentration of solids (10\% and $20 \%$ ), whereas for the slurries of higher solid concentrations $(30 \%$, $40 \%$ and $50 \%$ ), the apparent viscosity values decreased with the increase of shear rate values. The increase of apparent viscosity with increase in shear rate is seen as the dilatants nature of slurry at lower solid concentrations (10\% and $20 \%)$. When the solid loading increased from $20 \%$ to $30 \%$, the apparent viscosity values decreased with respect to increase in the shear rate which is the indicative of pseudo plastic nature of the slurry for the higher solid loadings (30\%, 40\% and $50 \%$ ).

The data plotted in Fig.5(a)-(j) was cross plotted in Fig.6(a)-(j) as the variation of apparent viscosity with respect to dispersant dosage (constant shear rate curves: shear rate of $60,74,91.3,121$ and $160 \mathrm{~s}^{-1}$ ) for the five solids loadings. For $10 \%$ solid loading, the variations of apparent viscosity values with respect to dispersant loading are almost similar for the two dispersants for all shear rates. For the CWS at $20 \%$ solids loading, for all shear rates tested, the apparent viscosity values attained their minimum values at dispersant dosages of $1.5 \mathrm{~kg} /$ tonne for CMC and $8 \mathrm{~kg} /$ tonne for STPP.

Apparently, in cases of $30 \%, 40 \%$ and $50 \%$ solids loadings, for all shear rates tested, the apparent viscosity values attained their minimum values at a dispersant dosages of $1.5 \mathrm{~kg}$ /tonne with $\mathrm{CMC}$ as dispersant. However the minimum values of apparent viscosity with STPP as dispersant was seen at $6 \mathrm{~kg} /$ tonne. Interestingly, the effect of dispersant in reducing the apparent viscosity was absent for $30 \%$ slurry with STPP as dispersant in the range of shear rates tested. The agglomeration of particles due to the excessive dispersant dosage can increase the ionic strength of the slurry, which can be manifested as the formation of strong electrical double layers around the solid particles and thereby the electrostatic repulsive forces among the particles get reduced. As a result, the apparent viscosity increases with increase in dispersant dosage after the saturation limit [19].

The rheological properties of CWS can be greatly influenced by nature of surface charges induced by the dispersant with its addition to CWS. CMC which is anionic in nature was very much effective in reducing the viscosity of the CWS due to its capability to induce more surface charge on coal particles by the combination of steric effects and electrostatic repulsions [4]. This is the reason for the more effectiveness of CMC in comparison with STTP at the lower dispersant loadings. However, slight increase in the $\mathrm{CMC}$ above the minimum loading led to a sharp increase in the 


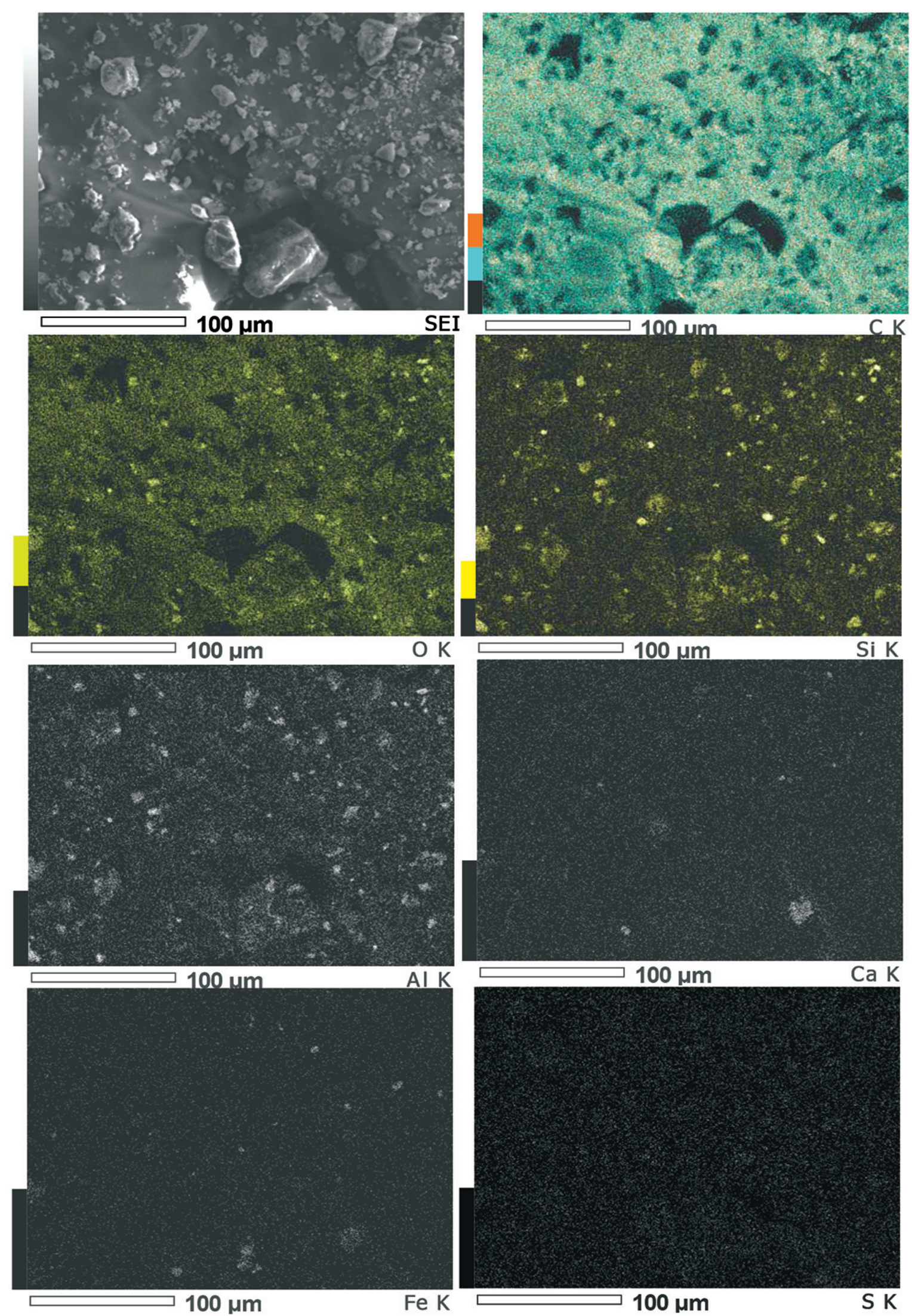

Fig.3: Scanning electron micrograph of coal sample and its elemental mapping of carbon, oxygen, silicon, aluminium, calcium, iron and sulphur 

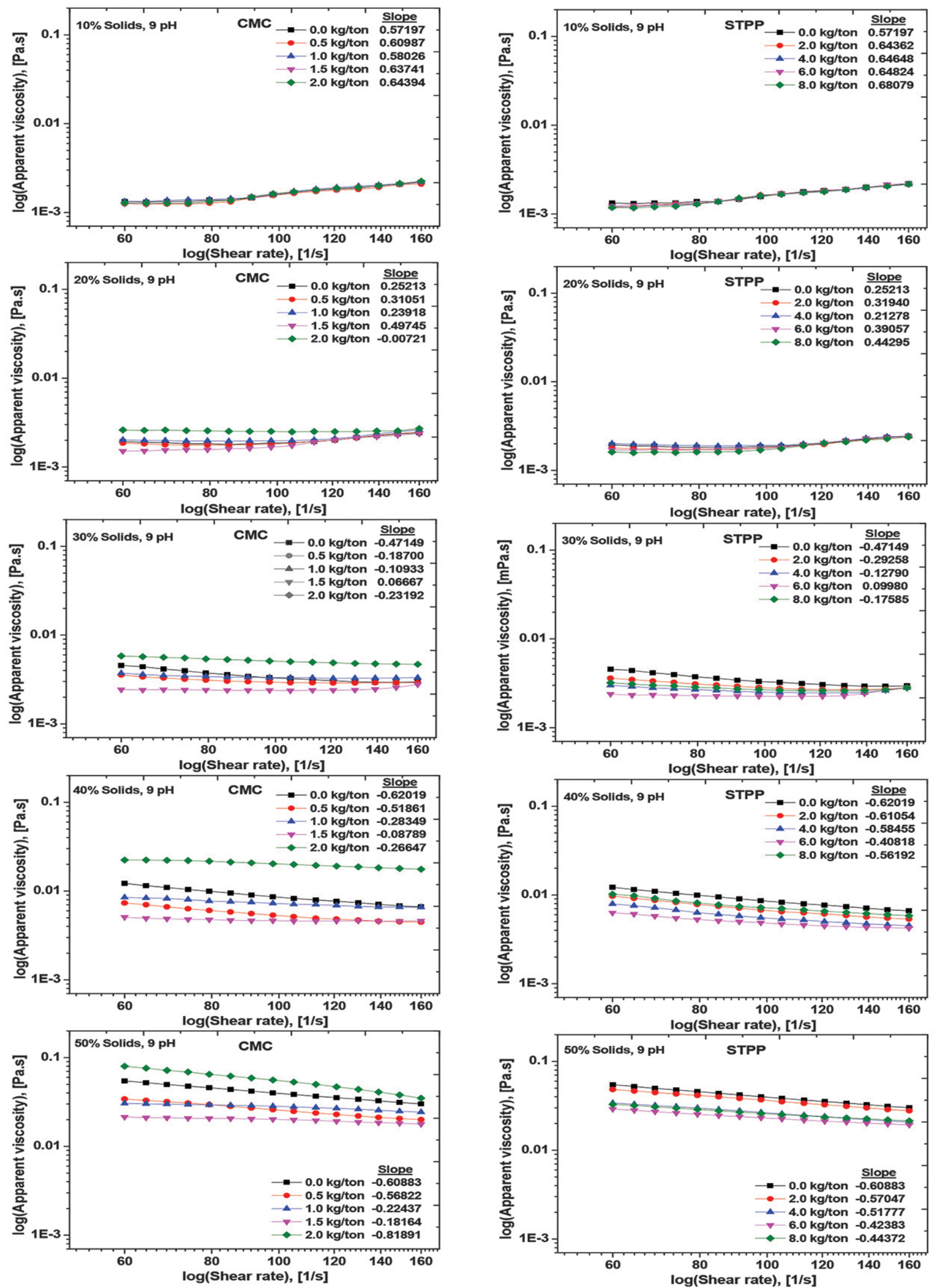

Fig.4: Shear stress versus shear rate on CWS at different solids loading

(a) $10 \%$, (c) $20 \%$, (e) $30 \%$, (g) $40 \%$ and (i) $50 \%$ for CMC, and (b) $10 \%$, (d) $20 \%$, (f) $30 \%$, (h) $40 \%$ and (j) $50 \%$ for STPP 

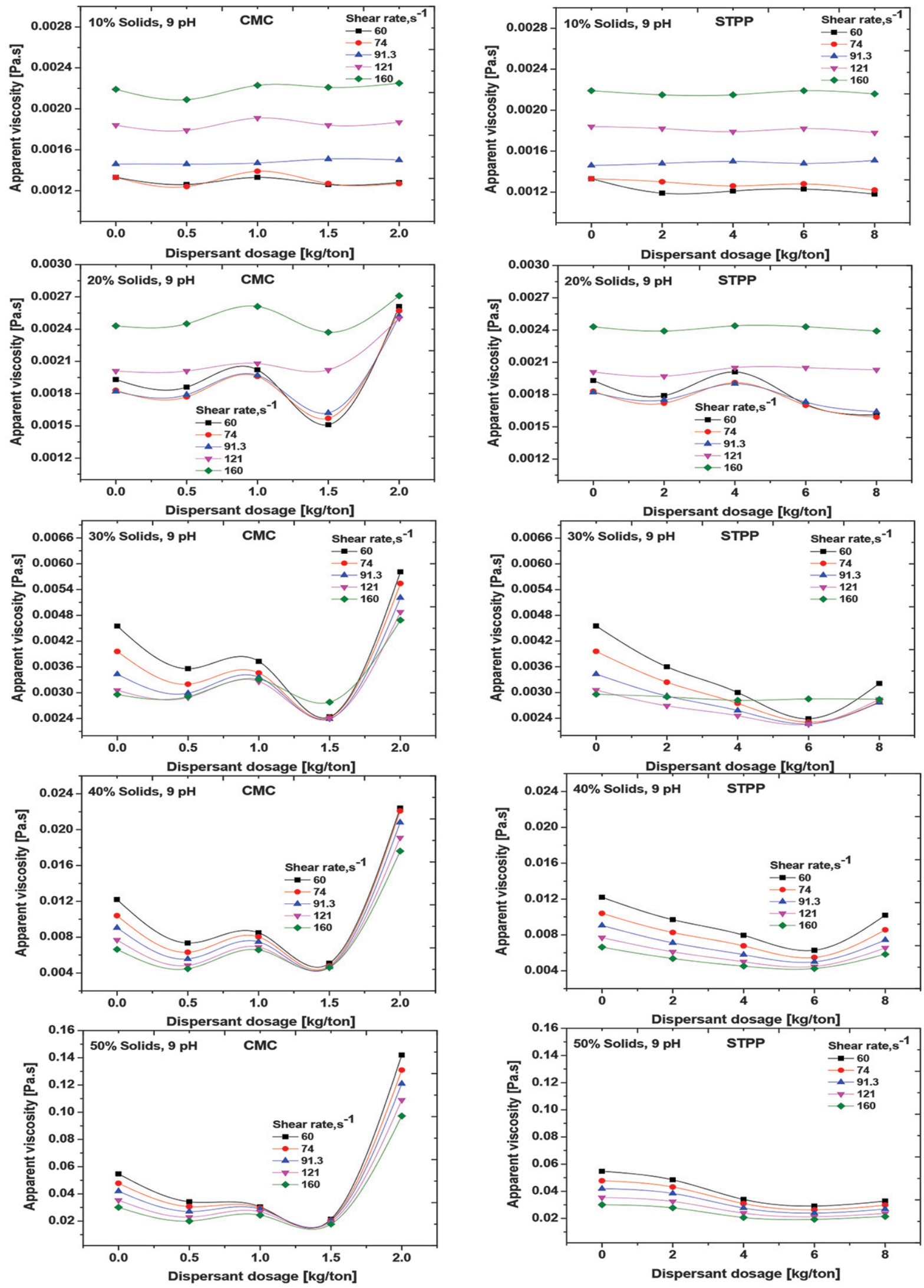

Fig.5: Effect of dispersant dosage on CWS at different solids loading

(a) $10 \%$, (c) $20 \%$, (e) $30 \%$, (g) 40\% and (i) 50\% for CMC, and (b) $10 \%$, (d) 20\%, (f) $30 \%$, (h) $40 \%$ and (j) $50 \%$ for STPP 

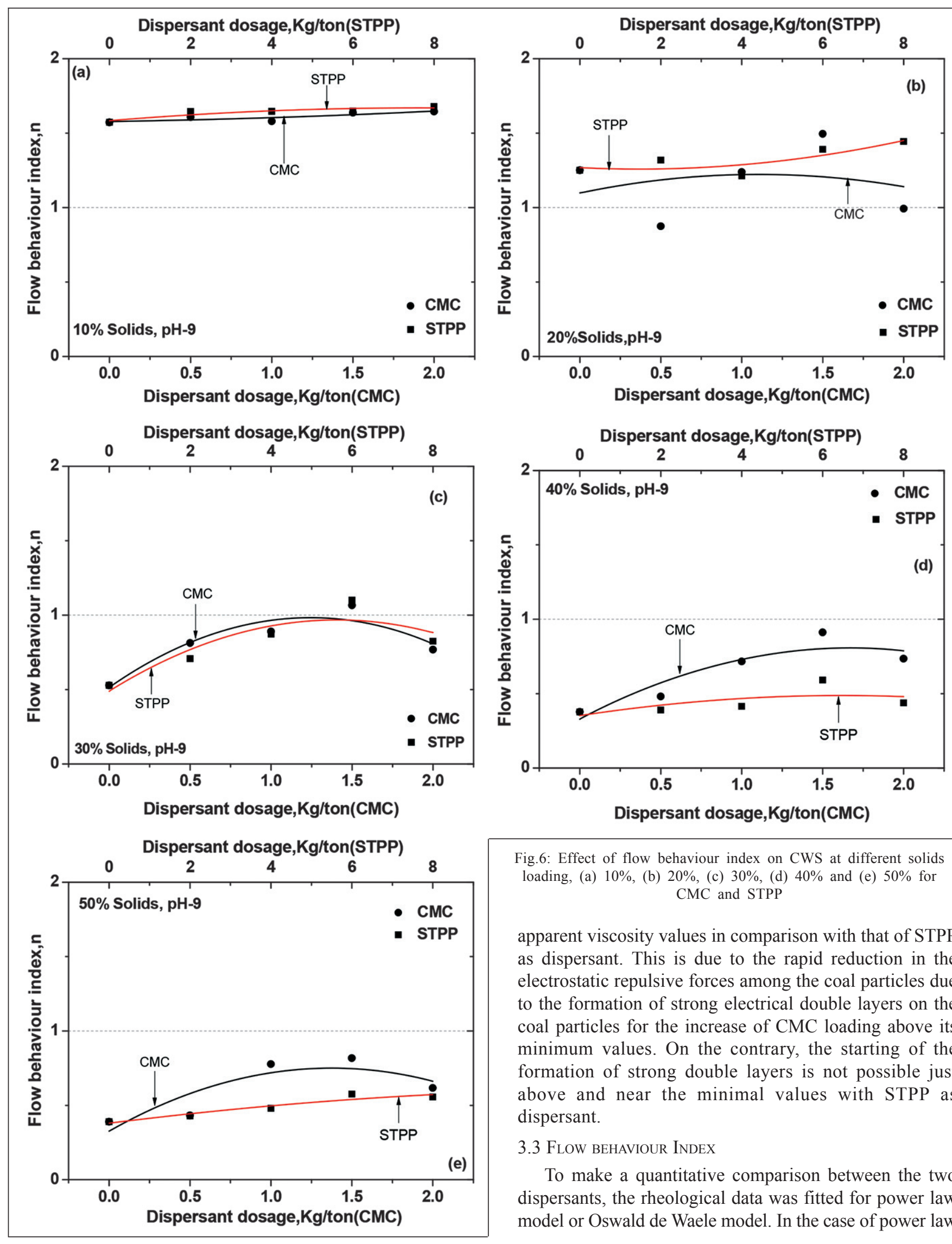

Fig.6: Effect of flow behaviour index on CWS at different solids loading, (a) $10 \%$, (b) $20 \%$, (c) $30 \%$, (d) $40 \%$ and (e) $50 \%$ for $\mathrm{CMC}$ and STPP

apparent viscosity values in comparison with that of STPP as dispersant. This is due to the rapid reduction in the electrostatic repulsive forces among the coal particles due to the formation of strong electrical double layers on the coal particles for the increase of CMC loading above its minimum values. On the contrary, the starting of the formation of strong double layers is not possible just above and near the minimal values with STPP as dispersant.

\subsection{Flow BeHAVIOUR INDEX}

To make a quantitative comparison between the two dispersants, the rheological data was fitted for power law model or Oswald de Waele model. In the case of power law 
model equation, the exponent of velocity gradient denoted generally with $n$ is famously called as flow behaviour index. The slurry can be denoted as Newtonian if the flow behaviour index is equal to 1 . For the two cases visually $n>1$ and $n<1$ (non-Newtonian $n \neq 1$ ), the rheological nature of the slurry is denoted as dilatants and pseudo plastic respectively. The variation of flow behaviour index values of two slurries for all solid loadings with respect to two dispersants are observed. For the two dispersants dilatants flow in nature or shear thickening behaviour was seen for the slurries of $10 \%$ and $20 \%$ solid loading. For the other three solid loadings $(30 \%$, $40 \%$ and $50 \%$ ), pseudo plastic flow in nature (shear thinning behaviour) can be seen as per the power law model. The transition from dilatants to pseudo plastic behaviour is observed when the solid concentration increased from $20 \%$ to $30 \%$. CWS with CMC as dispersant exhibited lower values of flow behaviour index (n) values in comparison with those of STPP at 10 and 20\% solids whereas higher and wider distribution of flow behaviour index values are reported for the slurries of $30 \%, 40 \%$ and $50 \%$ solid loading. Moreover, for a given solids loading, an increase of flow behaviour index values are evident with increase in dispersant dosage for both dispersants.

\subsection{Conclusion}

The rheological behaviour of the CWS was investigated for two different dispersants namely CMC (polymeric) and STPP (non-polymeric) and their effectiveness as dispersants were compared. After establishing the suitability of CMC and STPP as dispersants in the zeta potential and turbidity measurements, the rheological data was obtained in the shear rate range of $60-160 \mathrm{~s}^{-1}$. Most importantly, for a given solids concentration, the minimum values of shear stress were reported with a lower dispersant dosages with CMC as dispersant in comparison with STPP. In other words, for a given solids concentration, the dispersant dosage required to attain a value of shear stress for a given shear rate was lower for CMC in comparison with STPP. With CMC as dispersant, the coal surface can become aggressively negative even at lower dispersant loadings which can be seen as the increased repulsions among the coal particles by the combination of steric effects and electrostatic repulsions. Due to the higher sensitivity of the adsorption of CMC on coal particles with respect to loading, addition of dispersant beyond the saturation can be quite detrimental unlike the case with STPP.

For $10 \%$ and $20 \%$ solids loading, shear thickening (dilatent) nature was observed for the slurries for the two dispersants. For the other solid loadings (30\%, 40\% and 50\%) shear thinning (pseudo plastic) nature was observed for both the dispersants as the flow behaviour index values are less than 1. For a given dispersant and solids loading, the flow behaviour index values increased with increase in dispersant dosage.

\section{Acknowledgements}

The authors express their sincere thanks to Director, CSIRNational Metallurgical Laboratory, Jamshedpur, for his valuable guidance, encouragement and permission to publish this work.

\section{References}

[1]. Mishra, S.K. and Kanungo, S.B. (2000): Factor effecting the preparation of highly concentrated coal water slurry (HCCWS), Journal of Scientific \& Industrial Research 59 : 765-790. [http:// nopr.niscair.res.in/handle/123456789/26615]

[2]. Ahmed, SF and Hasan, AR. (1993): Rheology of low rank coal-water slurries at both high and low shear rates. Fuel. 72(6) : 763-69.[ https://doi.org/10.1016/ 0016-2361(93)90077-F].

[3]. Hasan, A.R. Baria, D.N. and Rao, A.V. (1986): Rheological behaviour of low-rank coal water slurries, Chem. Engg. Commn. Vol.46 : 227-240.[ DOI:10.1080/ 00986448608911409].

[4] Boylu, F., Ate ok, G. and Dinçer, H. (2005): The effect of carboxy methyl cellulose (CMC) on the stability of coal-water slurries, Fuel, 84: 315-319. [https://doi.org/ 10.1016/j.fuel.2003.12.016].

[5] Ananda Rao, M., Pavan Kumar, M.V. Subba Rao, S. and N. Narasaiah (2018): Rheological behaviour of coalwater slurry using sodium tripoly-phosphate as a dispersant, International Journal of Coal Preparation and Utilization, [DOI: 10.1080/ 19392699.2018.1485664]

[6]. Ananda Rao, M., Pavan Kumar, M.V., Subba Rao, S. and N. Narasaiah (2018): Rheological behaviour of coal-water slurries of Indian coals using carboxy methyl cellulose as dispersant- a comparative study, International Journal of Coal Preparation and Utilization, [DOI:10.1080/19392699.2018.1518901]

[7]. Das, Debadutta, Dash, Uma, Meher, Jibardhan and Misra, Pramila K. (2013). Improving stability of concentrated coal-water slurry using mixture of a natural and synthetic surfactants. Fuel Processing Technology. 113 : 41-51. [https://doi.org/10.1016/ j.fuproc.2013.02.021]

[8]. Yoon, S.J., Choi, Y.C. and Lee, J.G. (2009): The effect of additive chemicals on the viscosity of coal-petroleum coke-water slurry fuel for a gasification process Korean J. Chem. Eng. (2009) 26: 1259. [https://doi.org/ 10.1007/s11814-009-0223-6].

[9]. Ananda Rao, M., Yerriswamy, Veerapuram, Pavan Kumar, M.V. and Narasaiah, N. (2019): A comparative study on the rheological properties of two coal water slurries with sodium tripolyphosphate as dispersant, 
International Journal of Coal Preparation and Utilization, [DOI:10.1080/19392699.2019.1621300]

[10]. Phillip, R., Tudor, Dianne Atkinson, Crawford, Russell J. and Mainwaring, David E. (1996): The effect of adsorbed and non-adsorbed additives on the stability of coal-water suspensions. Fuel. 75(4): 443-452. [https://doi.org/10.1016/0016-2361(95)00267-7]

[11]. Eisa S. Mosa, abdel-Hady M. Saleh, Taha A. Taha and Anas M.El-Molla. (2008): Effect of chemical additives on flow characteristics of coal slurries. Physicochemical problems in mineral processing 42 :107-118. [http://www.minproc.pwr.wroc.pl/journal/pdf/ 2008/ FPM\%202008.pdf\#page=107].

[12] Dinçer, H., Boylu, F., Sirkeci, A.A., and Ate ${ }^{\circ}$ ok, G. (2003): The effect of chemicals on the viscosity and stability of coal water slurries, International Journal of Mineral Processing, 70 (1-4): 41-51. [https://doi.org/ 10.1016/S0301-7516(02)00149-7].

[13] Yu-Jen Shin and Yun-Hwei Shen. (2007): Preparation of coal slurry with organic solvents, Chemosphere, 68:389-393. [https://doi.org/10.1016/j.chemosphere. 2006.12.049].

[14] Pawlik, Marek (2005): Polymeric dispersants for coalwater slurries, Colloids and Surfaces A:
Physicochemical and Engineering Aspects, 266 (1-3): 82-90 [https://doi.org/10.1016/j.colsurfa.2005.04.043].

[15] Tadros, Th. F., Taylor, P. and Bognolo, G. (1995): Influence of addition of a polyelectrolyte, nonionic polymers, and their mixtures on the rheology of coal/ water suspensions. Langmuir 11 (12):4678-4684. [DOI: 10.1021/la00012a017].

[16] Saeki T., Tatsukawa, T., and Usui, H. (1999): Preparation Techniques of Coal Water Mixtures with Upgraded Low Rank Coals, Coal Preparation, 21:1, 161176, [DOI:10.1080/07349349908945615].

[17] Takashi Saeki, Hiromoto Usui, Masazo Ogawa (1994): Effect of Molecular Structure of Polysaccharide on the Stability of Coal-Water Mixtures, 27 (6 ): 773778. [https://doi.org/10.1252/jcej.27.773]

[18] Funk, J.E. (1979): Coal-water slurry and methods for its preparation, US Patent,No4468232. [https:// patents.google.com/patent/US4282006A/en].

[19] Papo, A., Piani, L. and Ricceri, R. (2002): Sodium tripoly phosphate and polyphosphate as dispersing agents for kaolin suspensions: rheological characterization, Colloids and Surfaces A: Physicochemical and Engineering Aspects 201 (1-3) :219-230. [https:// doi.org/10.1016/S0927-7757(01)01024-X].

\section{ASSESSMENT OF COAL PILLAR STABILITY USING PRINCIPAL COMPONENT ANALYSIS AND STEPWISE SELECTION AND ELIMINATION}

(Continued from page 87)

23. Song WD, Cao S, Fu JX, Jiang GJ, Wu F. (2014): Sensitivity analysis of impact factors of pillar stability and its application. Rock and Soil Mechanics. 35(1): 271-7.

24. Martin CD, Maybee WG. (2000): The strength of hardrock pillars. International Journal of Rock Mechanics and Mining Sciences. Dec 1;37(8):1239-46.

25. Bieniawski ZT. (1968): The effect of specimen size on compressive strength of coal. In International Journal of Rock Mechanics and Mining Sciences \& Geomechanics Abstracts, Jul 1 (Vol.5, No.4, pp.325335). Pergamon.

26. Van der Merwe JN. (2003): A laboratory investigation into the effect of specimen size on the strength of coal samples from different areas. Journal of the Southern
African Institute of Mining and Metallurgy. Jun 1; 103(5):273-9.

27. Trueman R, Mawdesley C. (2003): Predicting cave initiation and propagation. CIM bulletin. 96(1071): 549.

28. Madden BJ. (1991): A re-assessment of coal-pillar design. Journal of the Southern African Institute of Mining and Metallurgy. Jan 1;91(1):27-37.

29. Pearson K. LIII. (1901): On lines and planes of closest fit to systems of points in space. The London, Edinburgh, and Dublin Philosophical Magazine and Journal of Science. Nov 1; 2(11):559-72.

30. Hotelling H. (1933); Analysis of a complex of statistical variables into principal components. Journal of educational psychology. Sep; 24(6):417. 